\title{
黄淮海麦玉两熟区周年光温资源优化配置研究进展
}

\author{
周宝元 ${ }^{1}$ 葛均筑 ${ }^{2}$ 孙雪芳 $^{3}$ 韩玉玲 $^{1}$ 马 玮 ${ }^{1}$ 丁在松 ${ }^{1}$ 李从锋 $^{1}$ \\ 赵 明 1 ,*
}

${ }^{1}$ 中国农业科学院作物科学研究所 / 农业农村部作物生理生态与栽培重点开放实验室, 北京 $100081 ;{ }^{2}$ 天津农学院农学与资源环境学 院，天津 $300384 ;^{3}$ 青岛农业大学农学院，山东青岛 266109

摘 要: 在不增加任何成本前提下, 优化麦玉两熟周年光温资源配置是提升黄淮海区产量及资源利用效率的重要途 径之一。从 20 世纪 80 年代开始, 国内学者便从播/收期调整、不同生育期品种选育及新型种植模式创建等方面开展 了黄淮海麦玉两熟区周年光温资源高效利用途径探索。研究了小麦和玉米生长发育与光温资源的匹配关系，提出了 以强化 $\mathrm{C}_{4}$ 玉米” 高光效优势为核心的周年光温资源优化配置途径, 在冬小麦一夏玉米一年两熟基础上, 创新了冬小 麦一夏玉米“双晚”技术模式, 构建了冬小麦/春玉米/夏玉米、冬小麦/春玉米/夏玉米/秋玉米和双季玉米等种植模式, 实现了周年高产和光温资源高效利用。本文综述了黄淮海麦玉两熟种植模式周年光温资源优化配置研究进展及其在 麦玉两熟基础上的新型种植模式探索, 并提出了以积温分配为主的麦玉两熟制周年光温资源定量优化配置途径, 建 立了黄淮海区冬小麦一夏玉米一年两熟模式周年气候资源优化配置定量指标及其相应标准, 以期为进一步挖掘该区 周年产量及光温资源利用潜力提供新的思路及理论支撑。

关键词：黄淮海平原；冬小麦-夏玉米一年两熟；光温资源；优化配置

\section{Research advance on optimizing annual distribution of solar and heat resources for double cropping system in the Yellow-Huaihe-Haihe Rivers plain}

\author{
ZHOU Bao-Yuan ${ }^{1}$, GE Jun-Zhu ${ }^{2}$, SUN Xue-Fang ${ }^{3}$, HAN Yu-Ling ${ }^{1}$, MA Wei ${ }^{1}$, DING Zai-Song ${ }^{1}$, LI \\ Cong-Feng ${ }^{1}$, and ZHAO Ming ${ }^{1, *}$

\footnotetext{
${ }^{1}$ Institute of Crop Sciences, Chinese Academy of Agricultural Sciences / Key Laboratory of Crop Physiology and Production, Ministry of Agriculture and Rural Affairs, Beijing 100081, China; ${ }^{2}$ College of Agronomy \& Resource and Environment, Tianjin Agricultural University, Tianjin 300384, China; ${ }^{3}$ College of Agronomy, Qingdao Agricultural University, Qingdao 266109, Shandong, China
}

\begin{abstract}
Optimizing the distribution of annual solar and heat resources is an important way to improve the annual yield and resource use efficiency without increasing input for the winter wheat-summer maize of the Yellow-Huaihe-Haihe Rivers plain. During 1980s, the researchers began to explore ways to increase the efficiency utilization of solar and heat resources from the sowing/harvest adjustment, variety selection, and intensive cropping system innovation. Based on study of matching relation between crop growth and resources, a technological approach to optimize the distribution of solar and heat resources was put forward by strengthening the high photosynthetic efficiency of " $\mathrm{C}_{4}$ maize". Then, the winter wheat and summer maize "double late" technology, winter wheat/spring maize/summer maize, winter wheat/spring maize/summer maize/autumn maize cropping systems were established, which realized high yield and high efficient utilization of resources. In this paper, we reviewed current theoretical and regulation approaches for optimizing distribution of solar and heat resources of double cropping system in the Yellow-Huaihe-Haihe Rivers plain. Then proposed a quantitative and optimal resources distribution method for double cropping system, and set up the unified quantitative indexes for resources distribution between winter wheat and summer maize, which could provide theory support for further increasing anniversary production and resource utilization efficiency of the
\end{abstract}

本研究由国家重点研发计划项目(2018YFD0300504)和国家现代农业产业技术体系建设专项(CARS-02-12)资助。

This study was supported by the National Key Research and Development Program of China (2018YFD0200504) and the China Agriculture Research System (CARS-02-12).

*通信作者(Corresponding author): 赵明, E-mail: zhaoming@caas.cn, Tel: 010-82108752

第一作者联系方式: E-mail: zhoubaoyuan@caas.cn

Received (收稿日期): 2021-01-13; Accepted (接受日期): 2021-04-23; Published online (网络出版日期): 2021-05-06.

URL: https://kns.cnki.net/kcms/detail/11.1809.S.20210506.1305.002.html 
Yellow-Huaihe-Haihe Rivers plain.

Keywords: the Yellow-Huaihe-Haihe Rivers plain; winter wheat-summer maize double cropping system; solar and heat resources; optimizing distribution

黄淮海平原是我国重要的粮食产区, 也是典型 的两熟区域，冬小麦-夏玉米一年两熟为该区主要 种植体系, 其中小麦种植面积和产量分别占全国 $60 \%$ 和 50\%, 玉米种植面积和产量占全国 36\%和 $40 \%$ 左右, 为保障国家粮食安全发挥了重要作用 ${ }^{[1]}$ 。然而, 由于黄淮海资源短缺, 大部分地区麦玉两熟周年光 热资源紧张, 降水少且分布不均, 地下水过度开采 问题日益严重 ${ }^{[2-3]}$ 。特别是近年来, 受全球气候变暖 影响, 该区秋、冬季气温持续增加, 日照时数减少, 导致传统冬小麦-夏玉米一年两熟种植模式周年资 源配置不合理，作物品种、播期、生育期等与光、

温、水资源变化的匹配度下降 ${ }^{[4-7]}$, 限制了周年产量 及资源利用效率的进一步提升。同时, 气候变化引 起高温、干旱等极端天气频发, 导致冬小麦拔节孕 穗期遭受冻害、冬旱和春旱 ${ }^{[8]}$, 夏玉米授粉结实期 遭遇高温、干旱或阴雨寊照的风险进一步加剧 ${ }^{[9-10]}$ 。 另外, 由于化肥和灌溉投入量大, 及玉米机械化水 平低, 导致生产成本高, 增产不增收, 种植收益下 降。因此, 优化冬小麦-夏玉米周年气候资源配置, 并探索新型资源高效种植模式, 成为缓解气候变化 影响, 且在不增加投入的前提下, 进一步提升黄淮 海周年产量、资源利用效率及经济效益的重要途径。 本文总结了黄淮海麦玉两熟区种植模式发展历程及 其周年光温资源优化配置研究取得成果, 并结合本 团队多年研究结果提出了以积温分配为主的麦玉两 熟制周年资源精准配置技术途径, 建立了适应整个 黄淮海区冬小麦-夏玉米一年两熟生产的资源配置 定量指标及其相应标准, 以期为推动该区粮食生产 可持续发展提供理论依据和技术支撑。

\section{1 黄淮海麦玉两熟区种植模式发展历程}

黄淮海平原处于暖温带大陆性季风气候区, 该 区纬度跨度较大 $\left(31^{\circ} 23^{\prime} \sim 42^{\circ} 37^{\prime} \mathrm{N}\right)$, 气候资源分布不 均匀, 年 $\geq 10^{\circ} \mathrm{C}$ 积温为 $3600 \sim 4900^{\circ} \mathrm{C}$, 年累计日照 时数是 $2300 \sim 2800 \mathrm{~h}$, 年降雨量的范围是 $600 \sim 800$ $\mathrm{mm}$ 。长期以来, 该区的种植制度一直受制于热量资 源, 大部分地区光温资源一季有余、两季紧张。为 了充分利用全年有限光温资源, 提高周年产量和资 源利用效率, 在生产条件不断改善和生产水平不断 提高的前提下, 该区以小麦、玉米为核心的种植制
度经历了一系列的重大变革。

20 世纪 50 年代, 受作物品种、耕地质量、灌溉 设施及农业机械等生产条件限制, 该区小麦、玉米 等作物以一年一熟或两年三熟为主, 周年光温资源 利用潜力挖掘不足, 粮食单产不足 $1050 \mathrm{~kg} \mathrm{hm}^{-2} ; 60$ 年代至 70 年代, 以提高复种指数为主提高周年粮食 总产, 由于生产条件得到改善, 开始推行小麦/玉米 两茬套种, 以一年两熟为主, 周年产量和光温资源 利用效率显著提高; 70 年代至 80 年代, 以提高单产 和单位面积土地生产力为核心, 种植模式仍以小麦/ 玉米两茬套种为主, 并随着农业机械和农田灌溉的 发展及化学肥料的使用, 开始发展以早熟类型品种 为主的小麦、玉米两季平播, 最大限度利用周年光 温资源, 充分挖掘周年产量潜力; 80 年代后期, 注重 产量的同时开始关注经济效益, 该区一年两熟稳定, 耕作、播种及收获机械大面积应用, 开始推行晚播小 麦和夏播中晚熟玉米晚收的一年两熟种植制度, 并 结合多熟种植中长生育期高产作物, 充分发挥高产 作物的产量和资源利用潜力; 90 年代初, 随着机械 化水平不断提升, 灌溉设施不断完善及化肥投入增 加, 粮食产量水平得到大幅度提升, 开始重视质量 与效益, 高产高效逐渐成为这一时期种植制度的主 要特征 ${ }^{[1]}$, 进一步对种植业结构优化调整, 仍以冬 小麦-夏玉米一年两熟种植为主, 并在此基础上, 先 后探索了“冬小麦/春玉米/夏玉米” 和“冬小麦/春 玉米/夏玉米/秋玉米” 等集约多熟种植 ${ }^{[12-13]}$, 及轻简 高效的冬小麦-夏玉米“双晚” 技术模式 ${ }^{[14]}$, 进一步 提升了全年光温资源利用效率; 从 90 年代后期以来, 由于我国农产品供求格局发生了变化, 农民增收成 为重点关注的问题, 如何进一步提高该区周年机械 化水平和种粮经济效益成为热点, 在冬小麦-夏玉 米一年两熟基础上, 该区种植制度向多元化、高效 化方向发展, 充分运用新技术、新材料, 农艺与农机 结合, 并关注资源环境的可持续利用。

纵观黄淮海区种植制度的发展历程可知, 从小 麦、玉米一年一熟发展到两季套种, 再到两季平播, 目的是充分挖掘全年光温资源潜力, 提升周年粮食 产量, 技术策略是通过调整品种、播期等措施优化 配置周年光温资源, 实现全年光温资源最大化利 用。由于耕整地机械、播种及收获机械的广泛应用, 
及玉米少免耕播种技术的发展, 大大缩短了两季接 茬(整地、播种及收获)时间, 加之气候变暖增加了全 年积温量, 为两季平播, 及短生育期品种向中长生 育期的高产品种转换、播收期的调整提供了可能。 另外，增加高效作物(玉米)在周年种植中的比例，将 有效资源更多分配给更加高效的玉米生长季节中, 充分发挥高效作物潜能, 也是实现黄淮海麦玉两熟 区周年光温资源高效利用的重要途径。

\section{2 黄淮海麦玉两熟区周年光温资源优化配 置研究成果}

为充分挖掘黄淮海区周年光温资源潜力, 20 世 纪 80 年代开始许多农业科学家开展了大量以强化 $\mathrm{C}_{4}$ 作物-玉米高光温效率优势为核心的周年光温资 源高效利用途径探索, 或通过品种和播期调整等措 施优化冬小麦-夏玉米一年两熟周年光温资源配置, 或在冬小麦-夏玉米一年两熟基础上通过增加玉米 种植比例构建新型资源高效种植模式, 形成了一批 有代表性的成果, 在一定程度上大大提高了黄淮海 麦玉两熟区周年粮食产量和光温资源利用效率。

\section{1 小麦玉米生长发育与光温资源匹配关系研究}

为给黄淮海麦玉两熟周年光温资源优化配置提 供依据, 长期以来国内学者开展了大量关于小麦和 玉米生长发育与光温资源匹配的研究。尹钧团队 ${ }^{[15-16]}$ 研究了冬小麦产量与冬前积温量的关系, 明确了不 同春化特性小麦冬前积温需求和壮苗适宜叶龄指数, 及花后籽粒淀粉积累特性 ${ }^{[17]}$, 最终确立了在黄淮海 南部通过早播, 选用半冬性或半冬偏春性品种来提 高产量和资源利用效率的技术途径。Wang 等 ${ }^{[18]}$ 研究 结果表明, 较大幅度地推迟冬小麦播种期(11 月中旬), 通过选用大穗型品种、增加播种量, 依靠主茎成穗, 维持较高产量的同时可显著提高周年光温水等资源 利用效率。Zhou 等 ${ }^{[19]}$ 通过在河南北部设置大跨度播 期试验(10月上旬至 12 月初), 揭示了小麦分藮、叶 面积及干物质积累动态与各生育阶段光温变化的匹 配关系, 明确了小麦极晚播有利于躲避冬季冻害和 干旱，同时减少水分消耗并维持较高产量。董树亭 团队揭示了温度和光照等气候因素对玉米生长发育 及产量形成的影响机制, 明确了花后高温和寡照是 制约黄淮海夏玉米进一步高产的关键气候因素, 提 出了夏玉米直播晚收、延长灌浆时间、促进花后物质积 累的高产和光温资源高效利用栽培理论 ${ }^{[20-22]}$ 。李少昆 团队通过十余年黄淮海夏玉米区联网试验系统研究
了高产玉米群体生长发育与区域光热资源的定量匹 配关系, 认为该区玉米与光温资源匹配度偏低, 光 温利用效率只有 $60 \%$ 左右, 提出了选用生育期较长 品种并适时晚收的光温高效匹配途径 ${ }^{[23-24]}$ 。山东农业 大学经过系统研究表明, 宽窄行的株行距配置可以 优化高密度夏玉米群体光分布, 增加蓝紫光比例, 提高叶片光合能力, 由此提出了宽窄行密植的光能 高效利用途径 ${ }^{[25-26]}$ 。赵明团队 ${ }^{[27-29]}$ 利用播期模拟试 验探明了气候因子对玉米物质生产与产量形成的影 响机制, 建立了干物质积累和叶面积指数动态变化 的积温模型, 并提出了根据玉米不同收获目标的积 温需求确定收获期, 充分利用生育后期光温资源进行 籽粒脱水, 实现夏玉米籽粒机收的技术途径。

综上可知, 温度是影响冬小麦生长发育的主要 气候因素, 而辐射是夏玉米进一步高产的主要限制 因素。根据小麦和玉米对光温资源的需求特性, 确 定合理的品种更换、播收期调整及种植方式优化等 措施, 可以有效协调小麦和玉米生长发育与温度和 辐射的匹配关系, 从而进一步提高作物产量和光温 资源利用效率。

\section{2 冬小麦-夏玉米周年光温资源优化配置模式}

在黄淮海北部光热资源相对紧缺区, 为最大限 度利用有限光温资源, 提升冬小麦-夏玉米周年产量 和资源利用效率, 王树安 ${ }^{[14]}$ 建立了冬小麦-夏玉米 “双晚” 技术模式, 对周年光温资源进行再分配, 即将 冬小麦播种期由 10 月初推迟至 10 月中旬(晚播 5 7 d), 夏玉米收获期推迟至 9 月底至 10 月初(晚收 5 7 d), 在保证小麦产量不显著降低的情况下, 将更多 的资源分配给玉米, 使玉米产量显著增加, 实现了 周年高产和光温资源高效利用。应用“双晚”技术, 冬小麦-夏玉米周年产量可达 $15,000 \mathrm{~kg} \mathrm{hm}$ 以上, 光温资源生产力分别提高 $64 \%$ 和 $124 \%$, 在 20 世纪 90 年代首次创立了华北地区的“吨粮田”。Sun 等 ${ }^{[30]}$ 和 $\mathrm{Xu}$ 等 ${ }^{[31]}$ 对“双晚” 技术进行了试验验证, 结果表 明, 在不增加任何成本的前提下, 华北平原夏玉米 收获期和冬小麦播期分别推迟 $5 \mathrm{~d}$ 的“双晚” 种植 模式, 周年产量和水分生产效率均得到显著提升。 吕丽华等 ${ }^{[32]}$ 认为在河北平原小麦推迟播种时间、玉 米延迟收获时间是发挥两季作物均衡增产的重要措 施，小麦晚播至 10 月 17 日，玉米收获期推迟到 10 月 17 日, 积温可增加 $476^{\circ} \mathrm{C}$, 玉米可增产 $527.7 \mathrm{~kg}$ $\mathrm{hm}^{-2}$ 。付雪丽等 ${ }^{[33]}$ 研究得出, 冬小麦-夏玉米“双晚” 种植模式周年产量可达到 $21,891 \sim 22,507 \mathrm{~kg} \mathrm{hm}^{-2}$, 
比对照提高了 $442 \sim 2575 \mathrm{~kg} \mathrm{hm}^{-2}$, 周年光温资源生 产效率分别提高 $2.22 \% \sim 10.86 \%$ 和 $0.47 \% \sim 11.56 \%$ 。 另外, Wang 等 ${ }^{[34]}$ 利用 APSIM 模型研究了气候变化 对“双晚”技术增产效应的影响, 结果表明气候变 暖能够缓解晚播造成的小麦生育期缩短和产量降低, 并为夏玉米晚收提供了更多的积温保障, 可使冬小 麦-夏玉米“双晚” 技术模式周年产量提高 $4 \% \sim 6 \%$ 。

基于以上研究基础, 河北农业大学进一步深化 发展了适应河北水热资源紧缺条件的冬小麦-夏玉

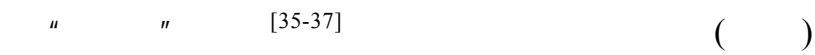
和行距配置高产小麦的光温利用效应和高产玉米生 育期调配的光温利用规律，提出了冬小麦“减温、 匀株” 和夏玉米“抢时、延收”的光温高效利用途 径, 即冬小麦晚播 4 7 d (冬前积温由 $640 \sim 680^{\circ} \mathrm{C}$ 减 至 $590^{\circ} \mathrm{C}$ 左右)和缩行密植(行距由 $20 \mathrm{~cm}$ 改为 $15 \mathrm{~cm}$ ), 培育冬前壮苗和合理群体, 提高光能截获率; 夏玉 米早播和晚收进行生育期调配, 充分利用冬小麦适 期晚播的余留光温, 挖掘玉米生产潜力, 实现了周 年产量和光温生产效率的同步提高。以上述研究内 容为核心, 形成了“海河平原小麦玉米两熟丰产高 效关键技术创新与应用”成果, 获 2011 年度国家科 技进步二等奖。

在黄淮海南部光热资源相对充足区, 针对玉米 收获至小麦播种空闲期过长造成资源严重浪费的问 题, 河南农业大学通过系统研究小麦品种的温光发 育特性 ${ }^{[15-17]}$, 建立了改弱春性(春性)品种为半冬性 (半冬偏春性)品种、改晚播为适当早播的双改技术”, 充分发挥了半冬性和半冬偏春性小麦品种冬前分蒒 多、分䔣成穗率高、穗分化时间长和穗重潜力大的 优势, 增加小麦对冬前光、温、水资源的有效利用; 探明了玉米高产群体生育和资源利用特征 ${ }^{[38]}$, 提出 了玉米壮根强株克服早衰延长生育期 10 15 d 的光 温高效利用途径，从而形成小麦“品种播期双改”、 玉米“延时收获”的周年资源高效利用技术，充分 利用两季接茬的空闲期, 周年可减少 $480 \sim 520^{\circ} \mathrm{C}$ 积 温和 240 260 $\mathrm{MJ} \mathrm{m}^{-2}$ 辐射的资源浪费, 实现了周年 高产和光温资源高效利用。以上述研究内容为核心, 形成了“黄淮区小麦夏玉米一年两熟丰产高效关键 技术研究与应用” 成果, 获 2010 年度国家科技进步 二等奖。

以上冬小麦-夏玉米一年两熟周年光温资源优 化配置模式均在一定程度上提高了周年产量和光温 资源利用效率，然而这些技术模式仍以经验性的调
播期和选品种为主, 具有区域局限性和随机性, 缺 乏共性的指导指标和定量依据, 难以精准指导区域 尺度的资源优化配置。

\section{3 集约多熟光温高效种植模式}

在黄淮海区种植模式发展过程中, 为了最大限 度地利用光照、温度、降水等自然资源, 提高周年 产量和资源利用效率, 许多科学家在冬小麦-夏玉 米一年两熟种植模式基础上也开展了以强化玉米高 光温效率优势为核心的多熟种植模式探索。逢焕成 等 ${ }^{[39]}$ 分析了小麦/玉米套种共生阶段的光温资源生 态效应与小麦边际效应, 认为适当增加玉米种植比 例可以显著提高小麦-玉米周年产量和光温资源利 用效率。陈阜等 ${ }^{[13]}$ 在冬小麦-夏玉米一年两熟的基础 上, 建立了“冬小麦/春玉米/夏玉米” 和“冬小麦/ 春玉米/夏玉米/秋玉米” 等集约多熟种植, 实现周年 平均产量达 $20,000 \mathrm{~kg} \mathrm{hm}^{-2}$ 以上。黄进勇等 ${ }^{[40]}$ 研究 表明冬小麦||春玉米-夏玉米复合种植模式主要通过 复合群体在田间高矮配合、生长发育进度交错, 使 各个作物的生殖生长时期均处于高空间生态位, 改 平面受光为立体受光, 改善了田间的生态条件, 从 而获得较高的产量和光温资源利用效率。赵秉强 等 ${ }^{[14]}$ 也认为, 小麦-玉米-玉米集约多熟高产技术模 式可实现全年光温资源高效利用, 达到 $18,000 \mathrm{~kg}$ $\mathrm{hm}^{-2}$ 的高产水平。Meng 等 ${ }^{[41]}$ 研究表明, 冬小麦/夏 玉米-春玉米两年三熟的种植模式, 由于部分减少 了小麦的种植, 年平均节约灌溉量可达 $40 \%$, 有利 于实现地下水平衡。可见, 在冬小麦-夏玉米两熟制 基础上, 通过对周年内种植作物比例进行调整, 适 当减少冬小麦种植面积, 增加玉米的种植面积, 也 是充分发挥玉米高光效优势, 实现周年高产和资源 高效利用的重要技术途径。陈阜等人联合完成的多 熟农作制丰产增效关键技术与集成应用”成果中对 黄淮海农区多熟种植制度产量及资源效率特征进行 了系统研究, 并建立了相应的丰产高效调控技术, 获 2018一-2019年度神农中华农业科技奖一等奖。然 而, 集约多熟种植模式属于高投入和高产出, 虽然 提高了周年产量和资源利用效率, 但增加了人工投 入, 且难以进行机械化操作, 针对当前农业生产规 模化、机械化和轻简化的发展形势, 麦玉两熟区集约 多熟种植模式及其配套栽培技术尚需要进一步简化。

\section{4 双季玉米新型光温高效种植模式}

为最大限度发挥玉米的高光温效率优势, 一些 科学家将冬小麦-夏玉米一年两熟模式中的小麦更 
换为光温高效的玉米, 探索并建立了双季玉米周年 高产高效种植模式。王美云等 ${ }^{[42]}$ 在黄淮海一年两熟 的北缘地区，进行了玉米地膜加套种的双作高产技 术模式探索, 研究结果表明, 双季青䛎玉米具有高 产高效特点, 两季不同熟期品种的配置使玉米生长 发育与自然资源的变化同步协调, 充分利用全年光 温资源。李立娟等 ${ }^{[43-44]}$ 在黄淮海中部地区探索了双 季连作粮用玉米模式, 两季均选择早熟品种, 早春 季覆膜早播(3 月 20 日左右), 及时收获(7 月 20 日左 右), 晚夏季抢时免耕直播(7 月 20 日左右), 适当晚 收(11 月上旬), 采用大小行双季交错连作的种植方 式，显著增加了周年作物产量、光温资源利用效率 以及经济效益。Meng 等 ${ }^{[45]}$ 研究表明, 双季玉米周年 产量可达到 $19.6 \mathrm{Mg} \mathrm{hm}^{-2}$, 与优化的冬小麦-夏玉米 一年两熟模式产量无显著差异，但是与传统的一年 两熟模式产量相比增加了 $21 \%$, 且双季玉米周年地 下水消耗量仅为 $139 \mathrm{~mm}$, 与一年两熟制的传统模式 和优化模式相比分别降低了 $136 \mathrm{~mm}$ 和 $69 \mathrm{~mm}$, 能够 维持地下水周年平衡。笔者利用 4 年定位试验对冬 小麦-夏玉米模式和双季玉米模式周年产量和资源 效率进行了比较, 结果表明, 二者周年产量无显著 差异, 但双季玉米模式周年光、温生产效率显著高 于冬小麦-夏玉米模式 ${ }^{[46]}$ 。另外, 这种种植方式不存 在共生期, 易于实现全程机械操作, 且冬季空余的 时间长达 $120 \mathrm{~d}$ 左右, 既能避免作物遭受冻害和冬 旱, 又有利于土壤中的有机物的积累和水分的储存, 使农田得到充分休养 ${ }^{[44]}$ 。可见, 双季玉米种植模式 由于其“双季 $\mathrm{C}_{4}$ 作物” 的合理搭配，具有产量潜力 高、光温水生产效率高的优点, 为进一步提升黄淮 海区周年产量潜力及资源效率提供了思路。然而, 由于春玉米季多次喷施农药为防止灰飞虫和粗缩病 的发生，导致双季玉米模式造成的潜在人体毒性、 水体毒性和土体毒性较为严重 ${ }^{[47]}$ 。另外, 冬小麦作 为口粮对保障我国粮食安全具有举足轻重的作用, 双季玉米模式的建立无法取代传统冬小麦-夏玉米 模式，只能作为一种有益的补充种植模式。

\section{3 黄淮海麦玉两熟周年光温资源精准配置 研究}

前人关于黄淮海麦玉两熟周年光温资源优化配 置与高效利用方面进行了大量的研究探索, 取得了 重要进展, 形成了一批有代表性的成果, 在一定程 度上大大提高了周年粮食产量和资源利用效率。然
而, 目前大部分研究往往仅以经验性的播期调整或 不同生育期品种选择进行周年资源优化配置, 缺乏 理论依据和定量指标的指导, 具有区域局限性和随 机性, 难以指导整个黄淮海麦玉两熟制周年光温资 源的精准配置。为此, 笔者在归纳总结前人研究与 本课题组 10 多年研究结果的基础上,于 2014 年全 国青年作物栽培与生理学术研讨会上提出了黄淮海 麦玉两熟周年光温资源定量配置途径，其核心是以 积温分配为主, 建立季节间积温分配率和分配比值, 及季节内积温满足率和光温生产潜力当量等定量化 指标, 并通过大量田间试验确定了实现冬小麦-夏 玉米周年高产高效的各指标定量标准，据此指导整 个黄淮海冬小麦-夏玉米模式周年资源精准配置。

\section{1 周年光温资源优化配置定量指标}

通过分析黄淮海麦玉两熟区的河南、河北、山 东 3 省 9 个试验点 5 年高产攻关田产量和光温资源 分配试验数据, 及河南新乡冬小麦-夏玉米播/收期 搭配的 6 年定位试验数据, 探明了气候因子与作物 产量的定量关系 ${ }^{[19,27-28]}$, 揭示了积温在周年气候资 源配置与种植模式构建中的主控作用, 由此提出了 以调节热量分布与作物需求平衡为核心的周年资源 优化配置途径。首次创立了以积温分配为主, 兼顾 辐射和降水分配的季节间资源优化配置定量指标, 并建立了相应的计算公式(表 1$)^{[48-49]}$ 。

\section{2 周年光温资源利用评价定量指标}

通过分析年际间、地区间生态条件的差异及光 温资源与产量形成的定量关系, 本团队首次提出了 表征季节内作物对光温资源挖掘利用程度的“光温 生产潜力当量” 指标及其计算公式(表 1), 即作物实 际产量与光温生产潜力的比值 ${ }^{[50]}$, 克服了以实际产 量评价存在区域光温资源禀赋差异影响的问题, 提 高了对作物光温资源利用程度评价的准确度。另外, 为评价资源变化与作物需求匹配关系, 建立了季节 内积温满足率 (accumulated temperature satisfaction rate, TSR)指标及公式(表 1), 即当地可利用积温总 量与作物生育期积温需求总量的比值, 用于精准指 导适宜熟期品种和播期选择及其种植安全性评价。

\section{3 周年光温资源优化配置与利用评价指标的} 定量标准

利用 2006-2010 年黄淮海区的河南(浚县、兰 考和温县)、河北(吴桥和䔄城)、山东(充州、滕州、 诸城和莱州) 9 个高产点共 45 个田间试验数据, 定 量分析了冬小麦-夏玉米模式高产形成与季节间光 
表 1 光温水资源定量配置与利用评价指标及其计算公式

Table 1 The quantitative index and formula of resource distribution and utilization

\begin{tabular}{|c|c|c|c|}
\hline 指标 Index & 公式 Formula & 指标 Index & 公式 Formula \\
\hline 积温分配率 TDR & $\begin{array}{l}\text { 单季积温量/周年积温总量 } \\
\text { Single seasonal AT of annual AT }\end{array}$ & 两季积温比值 TR & $\begin{array}{l}\text { 第一季积温量/第二季积温量 } \\
\text { First season AT/second season AT }\end{array}$ \\
\hline 辐射分配率 RDR & $\begin{array}{l}\text { 单季辐射量/周年辐射总量 } \\
\text { Single seasonal Ra of annual Ra }\end{array}$ & 两季辐射比值 RR & $\begin{array}{l}\text { 第一季辐射量/第二季辐射量 } \\
\text { First season Ra/second season Ra }\end{array}$ \\
\hline 降水分配率 PDR & $\begin{array}{l}\text { 单季降雨量/周年降雨总量 } \\
\text { Single seasonal Pr of annual Pr }\end{array}$ & 两季降水比值 PR & $\begin{array}{l}\text { 第一季降雨量/第二季降雨量 } \\
\text { First season } \operatorname{Pr} / \text { second season } \operatorname{Pr}\end{array}$ \\
\hline 光温生产潜力当量 TPPE & $\begin{array}{l}\text { 实际产量/光温生产潜力 } \\
\text { Yield/AT and Ra production potential }\end{array}$ & $\begin{array}{l}\text { 积温满足率 TSR } \\
\text { AT satisfaction rate }\end{array}$ & $\begin{array}{l}\text { 周年可利用积温量/作物积温需求量 } \\
\text { Annual AT/AT required by crop }\end{array}$ \\
\hline
\end{tabular}

AT: 积温; $\mathrm{R}_{\mathrm{a}}$ : 辐射; Pr: 降水量。

AT: accumulated temperature; TDR: accumulated temperature distribution rate; TSR: accumulated temperature satisfaction rate; TR: accumulated temperature ratio between two seasons; Ra: accumulated radiation; RDR: radiation distribution rate; RR: radiation ratio between two seasons; Pr: precipitation; PDR: precipitation distribution rate; PR: precipitation ratio between two seasons; TPPE: AT and Ra production potential equivalent.

温水资源分配的关系，明确了冬小麦-夏玉米周年 高产条件下的季节间有效积温(表 2)、辐射(表 3)及 降水(表 4)的定量分配特征 ${ }^{[48]}$ 。可以看出, 各省冬小 麦-夏玉米模式季节间热量和辐射资源分配量差异 较大，而季节间积温和辐射的分配率和分配比值无 显著差异，小麦季和玉米季积温分配率分别为 $43 \%$ 和 $57 \%$, 两季积温量比值为 0.7 , 辐射分配率分别为 $58 \%$ 和 $42 \%$ ，两季辐射量比值为 1.4 , 降水分配区域 间差异较大, 降水分配率变化范围分别为 $24 \%$ 29\%
和 $71 \% \sim 76 \%$ 。说明虽然区域间冬小麦-夏玉米两季 光温资源分配量差异较大, 但获得周年高产的两季 积温和辐射分配率和分配比值相对固定, 因此该指 标可作为整个黄淮海区冬小麦-夏玉米模式季节间 资源合理配置的定量标准。

同时，计算了 2006-2010 年河南、河北、山东 3 省 12 个高产点冬小麦-夏玉米光温生产潜力, 并根 据实际高产产量进一步计算出冬小麦-夏玉米高产 模式光温生产潜力当量值(表 5) ${ }^{[50]}$ 。可以看出, 虽然

\section{表 2 冬小麦-夏玉米高产模式周年积温分配}

Table 2 Annual accumulated temperature distribution for winter wheat-summer maize cropping systems

\begin{tabular}{|c|c|c|c|c|c|c|}
\hline \multirow{2}{*}{$\begin{array}{l}\text { 地点 } \\
\text { Site }\end{array}$} & \multicolumn{2}{|c|}{ 冬小麦 Winter wheat } & \multicolumn{2}{|c|}{ 夏玉米 Summer maize } & \multicolumn{2}{|c|}{ 周年 Annual } \\
\hline & $\begin{array}{c}\text { 积温 } \\
\text { AT }\left({ }^{\circ} \mathrm{C}\right) \\
\end{array}$ & $\begin{array}{c}\text { 分配率 } \\
\text { TDR (\%) }\end{array}$ & $\begin{array}{c}\text { 积温 } \\
\text { AT }\left({ }^{\circ} \mathrm{C}\right) \\
\end{array}$ & $\begin{array}{c}\text { 分配率 } \\
\text { TDR (\%) }\end{array}$ & $\begin{array}{c}\text { 积温 } \\
\text { AT }\left({ }^{\circ} \mathrm{C}\right) \\
\end{array}$ & $\begin{array}{c}\text { 两季比 } \\
\text { TR }\end{array}$ \\
\hline 河南 Henan & $2346.2 \mathrm{a}$ & 43 & $3142.3 \mathrm{a}$ & 57 & $5488.6 \mathrm{a}$ & 0.7 \\
\hline 山东 Shandong & $2263.6 \mathrm{~b}$ & 43 & $2983.0 \mathrm{~b}$ & 57 & $5245.8 \mathrm{~b}$ & 0.7 \\
\hline 河北 Hebei & $2135.0 \mathrm{c}$ & 43 & $2865.9 \mathrm{c}$ & 57 & $5000.9 \mathrm{c}$ & 0.7 \\
\hline
\end{tabular}

标以不同小写字母的各省平均产量在 0.05 水平差异显著。

AT: accumulated temperature; TDR: accumulated temperature distribution rate; TR: accumulated temperature ratio between two seasons. Values followed by different letters are significantly different in grain yield among the provinces at the 0.05 probability level.

表 3 冬小麦-夏玉米高产模式周年辐射分配

Table 3 Annual radiation distribution for winter wheat-summer maize cropping systems

\begin{tabular}{|c|c|c|c|c|c|c|}
\hline \multirow{2}{*}{$\begin{array}{l}\text { 地点 } \\
\text { Site }\end{array}$} & \multicolumn{2}{|c|}{ 冬小麦 Winter wheat } & \multicolumn{2}{|c|}{ 夏玉米 Summer maize } & \multicolumn{2}{|c|}{ 周年 Annual } \\
\hline & $\begin{array}{c}\text { 辐射量 } \\
\mathrm{Ra}\left(\mathrm{MJ} \mathrm{m}^{-2}\right)\end{array}$ & $\begin{array}{c}\text { 分配率 } \\
\text { RDR (\%) }\end{array}$ & $\begin{array}{c}\text { 辐射量 } \\
\mathrm{Ra}\left(\mathrm{MJ} \mathrm{m}^{-2}\right)\end{array}$ & $\begin{array}{c}\text { 分配率 } \\
\text { RDR (\%) }\end{array}$ & $\begin{array}{c}\text { 辐射量 } \\
\mathrm{Ra}\left(\mathrm{MJ} \mathrm{m}^{-2}\right)\end{array}$ & $\begin{array}{c}\text { 两季比 } \\
\text { RR }\end{array}$ \\
\hline 河南 Henan & $2437.7 \mathrm{~b}$ & 59 & $1687.2 \mathrm{~b}$ & 41 & $4124.9 \mathrm{~b}$ & 1.4 \\
\hline 山东 Shandong & $2659.7 \mathrm{a}$ & 58 & $1924.5 \mathrm{a}$ & 42 & $4547.6 \mathrm{a}$ & 1.4 \\
\hline 河北 Hebei & $2636.3 \mathrm{a}$ & 58 & $1857.7 \mathrm{a}$ & 42 & $4494.0 \mathrm{a}$ & 1.4 \\
\hline
\end{tabular}

标以不同小写字母的各省平均产量在 0.05 水平差异显著。

Ra: accumulated radiation; RDR: radiation distribution rate; RR: radiation ratio between two seasons. Values followed by different letters are significantly different in grain yield among the provinces at the 0.05 probability level. 
表 4 冬小麦-夏玉米高产模式周年降水分配

Table 4 Annual precipitation distribution for winter wheat-summer maize cropping systems

\begin{tabular}{|c|c|c|c|c|c|c|}
\hline \multirow{2}{*}{$\begin{array}{l}\text { 地点 } \\
\text { Site }\end{array}$} & \multicolumn{2}{|c|}{ 冬小麦 Winter wheat } & \multicolumn{2}{|c|}{ 夏玉米 Summer maize } & \multicolumn{2}{|c|}{ 周年 Annual } \\
\hline & $\begin{array}{l}\text { 降水量 } \\
\operatorname{Pr}(\mathrm{mm})\end{array}$ & $\begin{array}{c}\text { 分配率 } \\
\text { PDR (\%) }\end{array}$ & $\begin{array}{l}\text { 降水量 } \\
\operatorname{Pr}(\mathrm{mm})\end{array}$ & $\begin{array}{c}\text { 分配率 } \\
\text { PDR (\%) }\end{array}$ & $\begin{array}{l}\text { 降水量 } \\
\operatorname{Pr}(\mathrm{mm})\end{array}$ & $\begin{array}{c}\text { 两季比 } \\
\text { PR }\end{array}$ \\
\hline 河南 Henan & $160.9 \mathrm{~b}$ & 29 & $393.2 \mathrm{~b}$ & 71 & $554.1 \mathrm{~b}$ & 0.4 \\
\hline 山东 Shandong & $193.2 \mathrm{a}$ & 25 & $582.8 \mathrm{a}$ & 75 & $776.0 \mathrm{a}$ & 0.3 \\
\hline 河北 Hebei & $117.5 \mathrm{c}$ & 24 & $366.5 \mathrm{c}$ & 76 & $484.0 \mathrm{c}$ & 0.3 \\
\hline
\end{tabular}

标以不同小写字母的各省平均产量在 0.05 水平差异显著。

Pr: precipitation; PDR: precipitation distribution rate; PR: precipitation ratio between two seasons. Values followed by different letters are significantly different in grain yield among the provinces at the 0.05 probability level.

表 5 冬小麦-夏玉米高产模式产量、光温生产潜力和光温生产潜力当量

Table 5 Grain yield, radiation and temperature production potential, radiation and temperature production potential equivalent of winter wheat-summer maize cropping system

\begin{tabular}{|c|c|c|c|c|c|c|}
\hline \multirow{3}{*}{$\begin{array}{c}\text { 地点 } \\
\text { Site }\end{array}$} & \multicolumn{3}{|c|}{ 冬小麦 Winter wheat } & \multicolumn{3}{|c|}{ 夏玉米 Summer maize } \\
\hline & 产量 & 光温生产潜力 & 光温生产 & 产量 & 光温生产潜力 & 光温生产 \\
\hline & $\begin{array}{c}\text { Yield } \\
\left(\mathrm{kg} \mathrm{hm}^{-2}\right)\end{array}$ & $\begin{array}{c}\text { TPPy } \\
\left(\mathrm{kg} \mathrm{hm}^{-2}\right) \\
\end{array}$ & $\begin{array}{l}\text { 潜力当量 } \\
\text { TPPE (\%) }\end{array}$ & $\begin{array}{c}\text { Yield } \\
\left(\mathrm{kg} \mathrm{hm}^{-2}\right)\end{array}$ & $\begin{array}{c}\text { TPPy } \\
\left(\mathrm{kg} \mathrm{hm}^{-2}\right) \\
\end{array}$ & $\begin{array}{l}\text { 潜力当量 } \\
\text { TPPE (\%) }\end{array}$ \\
\hline 河南 Henan & $10,626.9 \mathrm{a}$ & $17,887.2 \mathrm{a}$ & $59.4 \mathrm{a}$ & $13,178.4 \mathrm{~b}$ & $19,868.2 \mathrm{~b}$ & 66.3 a \\
\hline 山东 Shandong & $10,391.6 \mathrm{a}$ & $17,502.3 \mathrm{a}$ & $59.3 \mathrm{a}$ & $14,350.4 \mathrm{a}$ & $21,162.8 \mathrm{a}$ & $67.8 \mathrm{a}$ \\
\hline 河北 Hebei & $9407.8 \mathrm{~b}$ & $15,732.8 \mathrm{~b}$ & $59.8 \mathrm{a}$ & $10,951.5 \mathrm{c}$ & $16,896.8 \mathrm{c}$ & $64.8 \mathrm{a}$ \\
\hline
\end{tabular}

标以不同小写字母的各省平均产量在 0.05 水平差异显著。

TPPy: AT and Ra production potential; TPPE: AT and Ra production potential equivalent. Values followed by different letters are significantly different in grain yield among the provinces at the 0.05 probability level.

各省光温生产潜力和实际产量差异显著, 但光温生 产潜力当量无显著差异, 说明在当时的生产技术水 平和品种产量潜力条件下各省对光温生产潜力的挖 掘水平差异不显著。因此，由于该指标消除了各地 光温资源禀赋差异的影响, 作为各地高产挖潜程度 和光温资源利用程度的评价标准更客观。

\section{4 周年光温资源定量优化配置体系应用实例}

在黄淮海麦玉两熟周年生产中, 北部光热资源 相对紧缺区, 冬小麦播种过早导致夏玉米成熟度低, 限制周年产量提升; 南部光热资源相对充足区，玉 米收获至小麦播种空闲期过长造成资源严重浪费, 而传统的通过调整播收期、选用不同熟期品种进行 种植模式优化的手段, 具有区域局限性和随机性, 难以建立整个区域统一的标准，导致区域间产量和 管理水平差异大。本研究基于该区从北向南周年可 利用积温 $4500 \sim 5600^{\circ} \mathrm{C}$ 总量, 以两季积温分配率 43\%：57\%为标准对整个黄淮海冬小麦-夏玉米模式 积温分配进行调整。北部积温紧张区, 选用半冬性 小麦品种晚播(5 7 d), 中熟品种玉米晚收(5 7 d), 将小麦季 $210 \sim 290^{\circ} \mathrm{C}$ 积温调至玉米季, 发挥玉米高 光效优势，延长灌浆期增粒重增产，小麦通过匀播 密植实现保穗稳产; 南部积温充足区，选用半冬性
或偏春性晚熟小麦品种早播(6 8 d), 中晚熟品种玉 米晚收 (7 10 d), 两季共用休闲期 $450 \sim 520^{\circ} \mathrm{C}$ 积温和 240 260 $\mathrm{MJ} \mathrm{m}^{-2}$ 辐射; 为实现冬小麦一夏玉米一年两 熟条件下的玉米籽粒低水分机械收获直接入库, 将 两季积温分配率调为 $34 \%$ 和 $66 \%{ }^{[49]}$ ，小麦极晚播至 冬前露头或不出苗状态, 让出 $550-650^{\circ} \mathrm{C}$ 积温给玉 米用于籽粒脱水，通过篮选适宜小麦品种和调整行 株距配置密植, 维持较高产量, 玉米选用抗倒脱水 快品种, 收获籽粒含水量达 $16 \%$ 以下, 形成小麦-玉 米周年双籽粒机收技术模式，在周年产量不降低的 前提下生产效率提高 $13.2 \%$ 。3 种优化模式下，小麦 和玉米生长季的积温分配量分别为 $2135^{\circ} \mathrm{C}$ 和 2866 ${ }^{\circ} \mathrm{C} 、 2346^{\circ} \mathrm{C}$ 和 $3142^{\circ} \mathrm{C} 、 1596^{\circ} \mathrm{C}$ 和 $3573^{\circ} \mathrm{C}$, 光温生产 潜力当量分别达到 $59.7 \%$ 和 $65.6 \%$ 、58.9\%和 $67.2 \%$ 、 $60.1 \%$ 和 $64.9 \%$, 均达到了当地高产水平。

以上述研究内容为核心，形成了“玉米温光资 源定量优化增产增效技术与应用”成果，获 20182019 年度神农中华农业科技奖一等奖。

4 黄淮海麦玉两熟周年资源优化配置研究展望

经过长期研究与生产实践, 研究人员已经建立 了大量适应黄淮海麦玉两熟区生态和生产特点的光 
温资源优化配置与高效利用模式，在保障国家粮食 安全和农民增收中发挥了巨大的作用。笔者基于前 人研究基础和本课题组十余年的研究结果, 通过定 量分析冬小麦-夏玉米两熟种植模式季节间光温资 源分配与利用特征, 及作物生产过程与气候因素的 内在关系, 初步建立了黄淮海麦玉两熟制周年光温 资源优化配置定量指标及资源高效利用技术体系, 弥补了现有气候资源配置定量指标的不足, 以期为 该区麦玉两熟种植制度优化提供思路和借鉴。然而, 在气候持续变暖的影响下, 及未来生产条件和生产 目标的不断变化, 黄淮海麦玉两熟制将迎接新的挑 战，在保证持续稳定增产的前提下，该区种植制度 应逐步走向资源高效化、规模机械化、精准信息化、 经济效益及环境可持续。

\section{1 适应气候变暖趋势的麦玉两熟周年资源优} 化配置研究

在气候变暖的影响下, 积温的增加使麦玉两熟 区北界向北推移, 也会导致当前的品种类型发生变 化, 冬小麦品种向冬性减弱的类型发展; 夏玉米生 育期热量条件得到改善, 能够满足中晚熟玉米品种 平播的热量需求 ${ }^{[7]}$, 特别是为夏玉米增加站秆脱水 时间, 实现机械直接收获籽粒提供了有利条件。另 外, 气候变化也将导致极端高温、低温、涝渍及干 旱等气象灾害频发, 影响冬小麦安全越冬和正常成 熟, 及夏玉米授粉结实及灌浆 ${ }^{[8,10]}$ 。因此, 针对未来 气候变化趋势, 黄淮海麦玉两熟种植制度的发展应 加强适应未来气候变暖条件的品种与播期合理搭 配、周年资源优化配置研究; 加强作物品种与温度 及水分的匹配关系研究, 开展应对极端温度、涝渍 或干旱等气象灾害的周年资源优化配置研究。

4.2 适应规模机械化生产的麦玉两熟周年资源 优化配置研究

以机械化为核心的规模化经营是降低生产成本, 提高种植效益的重要途径, 也是现代农业生产的必 然趋势。目前限制冬小麦-夏玉米两熟制全程机械化 的关键在于夏玉米籽粒机械收获, 两季作物竞争光 温资源导致夏玉米收获时籽粒含水量高, 破碎率、 杂质率高, 且籽粒烘干耗能大、成本高 ${ }^{[51]}$, 如何从种 植制度创新或两季资源优化配置角度探索实现夏玉 米机械直接收获籽粒的途径还有待进一步研究。另 外, 从粗放模式走向精准管理也是农业规模化生产 的必然需求, 作物生产全程标准化、精准化控制是 实现规模生产效应的关键。在明确作物生长与光温
水等条件定量关系基础上, 进一步建立定量指标及 计算公式, 可为精准管理决策提供基础数据和核心 算法。笔者前期初步建立了黄淮海麦玉两熟周年光 温资源配置定量指标, 随着气候变化和作物品种的 更新换代, 各指标参数需要进一步优化调整。另外, 如何将各定量指标高度融合, 建立简便易操作模型, 以便有效应用于生产实践, 尚有待进一步的研究。

4.3 适应水资源可持续利用的麦玉两熟周年资 源优化配置研究

水资源紧缺已成为黄淮海大部分地区冬小麦夏玉米一年两熟种植体系可持续发展的第一限制性 因素。周年降雨不足及其季节间的不均衡分布是造 成该体系大量消耗地下水的主要原因 ${ }^{[41,52]}$, 且气候 变暖导致降水资源的不确定性会进一步加剧地下水 资源的消耗。虽然针对单季作物的水分优化管理, 如根 层干湿交替灌溉、亏缺灌溉、限制性灌溉等, 能够较大 幅度提高水资源利用效率, 但为保证小麦高产仍需 250 $\mathrm{mm}$ 以上的灌水量 ${ }^{[33]}$, 不可避免地下水的过度消耗, 而 从种植系统降水资源优化配置角度探索实现冬小麦-夏 玉米周年水分平衡与高效利用的途径可能是解决这一 问题的出路。因此, 麦玉两熟种植体系未来应重点开展 以周年降水最大化利用为核心的麦玉两熟周年降水资 源优化配置研究与种植模式优化。

总之, 我国农业发展已经进入新的阶段, 从单 纯追求产量的粗放型向产量与效益并重的质量型发 展, 资源的高效利用及促进农民增收成为当前农业 生产的首要任务。因此, 笔者认为末来黄淮海麦玉 两熟种植制度发展的方向和目标仍然是经济效益、 生态效益和资源效率的持续高效, 在不增加任何投 入的前提下, 两季资源优化配置将继续在挖掘麦玉 两熟周年产量和资源利用潜力中发挥重要作用。

\section{References}

[1] 中华人民共和国农业农村部. 中国农业统计资料. 北京: 中国 农业出版社, 2015.

Ministry of Agriculture and Rural Affairs of the Peoples' Republic of China. China Agriculture Statistical Report. Beijing: China Agriculture Press, 2015 (in Chinese).

[2] Wang H X, Liu C M, Zhang L. Water-saving agriculture in China: an overview. Adv Agron, 2002, 75: 135-171.

[3] 费宇红, 张兆吉, 张凤娥, 王昭, 陈宗宇, 陈京生, 钱永, 李亚 松. 气候变化和人类活动对华北平原水资源影响分析. 地球 学报, 2007, 28: 567-571.

Fei Y H, Zhang Z J, Zhang F E, Wang Z, Chen Z Y, Chen J S, Qian Y, Li Y S. An analysis of the influence of human activity and climate change on water resources of the North China Plain. 
Acta Geosci Sin, 2007, 28: 567-571 (in Chinese with English abstract).

[4] Chen C, Wang E, Yu Q, Zhang Y Q. Quantifying the effects of climate trends in the past 43 years (1961-2003) on crop growth and water demand in the North China Plain. Climate Change, 2010, 100: 559-578.

[5] Tao F, Yokozawa M, Xu Y L, Hayashi Y, Zhang Z. Climate changes and trends in phenology and yields of field crops in China, 1981-2000. Agric For Meteorol, 2006, 138: 82-92.

[6] Dong J, Liu J, Tao F, Xu X, Wang J. Spatio-temporal changes in annual accumulated temperature in China and the effects on cropping systems, 1980s to 2000. Climate Res, 2009, 40: 37-48.

[7] 黄川荣, 刘洪. 气候变化对黄淮海平原冬小麦与夏玉米生产 潜力的影响. 中国农业气象, 2011, 32: 118-123.

Huang C R, Liu H. The effect of the climate change on potential productivity of winter wheat and summer maize in the Huang-Huai-Hai Plain. Chin J Agronmeteor, 2011, 32: 118-123 (in Chinese with English abstract).

[8] 蔡剑, 姜东. 气候变化对中国冬小麦生产的影响. 农业环境科 学学报, 2011,30: 1726-1733.

Cai J, Jiang D. The effect of climate change on winter wheat production in China. J Agrno-Environ Sci, 2011, 30: 1726-1733 (in Chinese with English abstract).

[9] Cairns J E, Sonder K, Zaidi P H, Verhulst N, Mahuku G, Babu R, Nair S K, Das B, Govaerts B, Vinayan M T, Rashid Z, Noor J J, Devi P, San Vicente F, Prasanna B M. Maize production in a changing climate: impacts, adaptation, and mitigation strategies. Adv Agron, 2012, 114: 1-58.

[10] Xiong W, Matthews R, Holman I, Lin E, Xu Y L. Modelling China's potential maize production at regional scale under climate change. Climate Change, 2007, 85: 433-451

[11］牟正国. 我国农作制度产业的新进展. 耕作与栽培, 1993，(3) $1-4$.

Mou Z G. New progress of China's farming system. Farm Cult, 1993, (3): 1-4 (in Chinese).

[12] 陈阜, 逢焕成. 冬小麦/春玉米/夏玉米间套作复合群体的高产 机理探讨. 中国农业大学学报, 2000, 5(5): 12-16.

Chen F, Pang H C. Research on mechanism for maximum yield of intercropping pattern wheat/corn/corn. J China Agric Univ, 2000, 5(5): 12-16 (in Chinese with English abstract).

[13] 赵秉强, 张福锁, 李增嘉, 李凤超, 劳秀荣, 史春余, 董庆裕, 张骏, 刘嘉军, 杨恩学. 黄淮海农区集约种植制度的超高产特 性研究. 中国农业科学, 2001, 34: 649-655.

Zhao B Q, Zhang F S, Li Z J, Li F C, Lao X R, Shi C Y, Dong Q Y, Zhang J, Liu J J, Yang E X. Studies on the super-high yield characteristics of three intensive multiple cropping systems in Huanghuaihai area. Sci Agric Sin, 2001, 34: 649-655 (in Chinese with English abstract).

[14] 王树安. 小麦-夏玉米平播亩产吨粮的理论与实践. 北京: 农 业出版社, 1991.

Wang S A. Theory and Practice High Yield Output of 15 Tons per Hectare in Winter Wheat and Summer Maize Double-Cropping System. Beijing: Agriculture Press, 1991 (in Chinese).

[15] Li Q Y, Yin J, Liu W D, Zhou S M, Li L, Niu J S, Niu H B, Ma Y. Determination of optimum growing degree-days (GDD) range before winter for wheat cultivars with different growth characteristics in North China Plain. J Integr Agric, 2012, 11: 405-415.

[16] Li Q Y, Li L, Niu J S, Yin J. Temperature impacts on wheat growth and yield in the North China Plain. Afr J Biotechnol, 2012, 11: 8992-9000.

[17] 张嫚, 周苏玫, 张甲元, 张洁梅, 李否, 李武超, 张珂珂, 尹钧. 不同温光型专用小麦品种花后旗叶生理与籽粒淀粉积累特性. 麦类作物学报, 2017, 37: 520-527.

Zhang M, Zhou S M, Zhang J Y, Zhang J M, Li L, Li W C, Zhang K K, Yin J. Physiological characteristics of flag leaf and starch accumulation in grains at post-anthesis of thermo-photo sensitive wheat (Triticum aestivum L.) cultivars for different end uses. $J$ Triticeae Crops, 2017, 37: 520-527 (in Chinese with English abstract).

[18] Wang B, Zhang Y H, Hao B Z, Xu X X, Zhao Z G, Wang Z M, $\mathrm{Xu} \mathrm{Q}$ W. Grain yield and water use efficiency in extremely-late sown winter wheat cultivars under two irrigation regimes in the North China Plain. PLoS One, 2016, 11: e0153695.

[19] Zhou B Y, Sun X F, Ge J Z, Ding Z S, Li C F, Ma W, Zhao M. Wheat growth and grain yield responses to sowing dateassociated variations in weather conditions. Agron J, 2020, 112: 985-997.

[20] 张保仁, 董树亭, 胡昌浩, 王空军. 高温对玉米籽粒淀粉合成 及产量的影响. 作物学报, 2007, 33: 38-42.

Zhang B R, Dong S T, Hu C H, Wang K J. Effect of high air temperature during different growth stage on starch synthesis in grain and yield in maize (Zea mays L.). Acta Agron Sin, 2007, 33: 38-42 (in Chinese with English abstract).

[21] 高佳, 史建国, 董树亭, 刘鹏, 赵斌, 张吉旺. 花粒期光照强 度对夏玉米根系生长和产量的影响. 中国农业科学, 2017, 50: 2104-2113.

Gao J, Shi J G, Dong S T, Liu P, Zhao B, Zhang J W. Effect of different light intensities on root characteristics and grain yield of summer maize (Zea mays L.). Sci Agric Sin, 2017, 50: 2104-2113 (in Chinese with English abstract).

[22] Liu Z, Gao J, Gao F, Liu P, Zhao B, Zhang J W. Late harvest improves yield and nitrogen utilization efficiency of summer maize. Field Crops Res, 2019, 232: 88-94.

[23] Liu Y E, Xie R Z, Hou P, Li S K, Zhang H B, Ming B, Long H L, Liang S M. Phenological responses of maize to changes in environment when grown at different latitudes in China. Field Crops Res, 2013, 144: 192-199.

[24] Liu Y E, Hou P, Xie R Z, Li S K, Zhang H B, Ming B, Ma D L, Liang S M. Spatial adaptabilities of spring maize to variation of climatic conditions. Crop Sci, 2013, 53: 1693-1703.

[25] 杨吉顺, 高辉远, 刘鹏, 李耕, 董树亭, 张吉旺, 王敬锋. 种植 密度和行距配置对超高产夏玉米群体光合特性的影响. 作物 学报, 2010, 36: 1226-1233.

Yang J S, Gao H Y, Liu P, Li G, Dong S T, Zhang J W, Wang J F. Effects of planting density and row spacing on canopy apparent photosynthesis of high-yield summer corn. Acta Agron Sin, 2010, 36: 1226-1233 (in Chinese with English abstract).

[26] 刘惠惠, 杨吉顺, 李耕, 刘鹏, 董树亭, 杨今胜, 柳京国. 种植 密度和行距配置对玉米穗位叶光合特性的影响. 山东农业科 
学, 2012, 44(5): 23-27.

Liu H H, Yang J S, Li G, Liu P, Dong S T, Yang J S, Liu J G. Effects of planting density and row spacing form on photosynthetic characters of maize ear leaf. Shandong Agric Sci, 2012, 44(5): 23-27 (in Chinese with English abstract).

[27] Zhou B Y, Yue Y, Sun X F, Wang X B, Wang Z M, Ma W, Zhao M. Maize grain yield and dry matter production responses to variations in weather conditions. Agron J, 2016, 108: 196-204.

[28] Zhou B Y, Yue Y, Sun X F, Ding Z S, Ma W, Zhao M. Maize kernel weight responses to sowing date-associated variation in weather conditions. Crop J, 2017, 5: 43-51.

[29] 李向岭, 赵明, 李从锋, 葛均筑, 侯海鹏. 玉米叶面积系数动 态特征及其积温模型的建立. 作物学报, 2011, 37: 321-330.

Li X L, Zhao M, Li C F, Ge J Z, Hou H P. Dynamic characteristics of leaf area index in maize and its model establishment based on accumulated temperature. Acta Agron Sin, 2011, 37: 321-330 (in Chinese with English abstract).

[30] Sun H Y, Zhang X Y, Chen S Y, Pei D, Liu C M. Effects of harvest and sowing time on the performance of the rotation of winter wheat-summer maize in the North China Plain. Ind Crops Prod, 2007, 25: 239-247.

[31] Xu C L, Zhao H X, Zhang P, Wang Y Y, Huang S B, Meng Q F, Wang $P$. Delaying wheat seeding time and maize harvest improved water use efficiency in a warm temperature continental monsoon climate. Agron J, 2018, 110: 1420-1429.

[32] 吕丽华, 董志强, 王学清, 刘茜, 张丽华, 贾秀领. 冬小麦晚 播、夏玉米晚收增产潜力分析. 华北农学报, 2019, 34: 36-42. Lyu L H, Dong Z Q, Wang X Q, Liu Q, Zhang L H, Jia X L. Analysis on potential of increasing production for late sow of winter wheat and late harvest of summer maize. Acta Agric Boreali-Sin, 2019, 34: 36-42 (in Chinese with English abstract).

[33] 付雪丽, 张惠, 贾继增, 杜立丰, 付金东, 赵明. 冬小麦-夏玉 米“双晚”种植模式的产量形成及资源效率研究. 作物学报, 2009, 35: 1708-1714.

Fu X L, Zhang H, Jia J Z, Du L F, Fu J D, Zhao M. Yield performance and resources use efficiency of winter wheat and summer maize in double late-cropping system. Acta Agron Sin, 2009, 35: 1708-1714 (in Chinese with English abstract).

[34] Wang J, Wang E L, Yang X G, Zhang F S, Yin H. Increased yield potential of wheat-maize cropping system in the North China Plain by climate change adaptation. Climate Change, 2012, 113: 825-840.

[35] 张敏, 王岩岩, 蔡瑞国, 李婧实, 王文颇, 周印富, 李彦生, 杨 树宗. 播期推迟对冬小麦产量形成和籽粒品质的调控效应. 麦类作物学报, 2013, 33: 325-330.

Zhang M, Wang Y Y, Cai R G, Li J S, Wang W P, Zhou Y F, Li Y S, Yang S Z. Regulating effect of delayed sowing date on yield formation and grain quality of winter wheat. $J$ Triticeae Crops, 2013, 33: 325-330 (in Chinese with English abstract).

[36] 秦乐, 王红光, 李东晓, 崔帅, 李瑞奇, 李赝鸣. 不同密度下 超窄行距对冬小麦群体质量和产量的影响. 麦类作物学报, 2016, 36: 659-667.

Qin L, Wang H G, Li D X, Cui S, Li R Q, Li Y M. Effect of super narrow row space on population quality and grain yield of winter wheat in different planting densities. $J$ Triticeae Crops, 2016, 36: 659-667 (in Chinese with English abstract).
[37] 张宁, 杜雄, 江东岭, 崔彦宏. 播期对夏玉米生长发育及产量 影响的研究. 河北农业大学学报, 2009, 32(5): 7-11.

Zhang N, Du X, Jiang D L, Cui Y H. Effect of sowing date on growth and yield of summer corn (Zea mays L.). J Hebei Agric Univ, 2009, 32(5): 7-11 (in Chinese with English abstract).

[38] 苏新宏, 张学林, 王群, 李潮海. 超高产栽培条件下气象条件 对夏玉米产量的影响. 玉米科学, 2009, 17(1): 105-107.

Su X H, Zhang X L, Wang Q, Li C H. Effects of meteorological factors on grain yield of summer corn under super-high-yield cultivation. J Maize Sci, 2009, 17(1): 105-107 (in Chinese with English abstract).

[39] 逢焕成, 宋吉作, 刘光亮. 小麦玉米套种共生期的气候生态效 应与小麦边际效应分析. 耕作与栽培, 1994, (4): 15-16.

Pang H C, Song J Z, Liu G L. Analysis of climatic ecological effect and wheat marginal effect in the interplanting period of wheat and maize. Farm Cult, 1994, (4): 15-16 (in Chinese).

[40] 黄进勇, 李新平, 孙敦立. 黄淮海平原冬小麦-春玉米-夏玉米 复合种植模式生理生态效应研究. 应用生态学报, 2003, 14(1): 51-56.

Huang J Y, Li X P, Sun D L. Ecophysiological effects of multiple cropping of winter wheat-spring corn-summer corn in Huanghuaihai Plain. Chin J Appl Ecol, 2003, 14(1): 51-56 (in Chinese with English abstract).

[41] Meng Q F, Sun Q P, Chen X P, Cui Z L, Yue S C, Zhang F S, Römheld V. Alternative cropping systems for sustainable water and nitrogen use in the North China Plain. Agric Ecosys Environ, 2012, 146: 93-102.

[42] 王美云, 任天志, 赵明, 李少昆, 王晓波, 李立娟, 陈长利. 双 季青咜玉米模式物质生产及资源利用效率研究. 作物学报, 2007, 33: 1316-1323.

Wang M Y, Ren T Z, Zhao M, Li S K, Wang X B, Li L J, Chen C L. Matter production and resources use efficiency of doublecropping silage maize system. Acta Agron Sin, 2007, 33: 1316-1323 (in Chinese with English abstract).

[43] 李立娟, 王美云, 赵明. 品种对双季玉米早春季和晚夏季的适 应性研究. 作物学报, 2011, 37: 1660-1665

Li L J, Wang M Y, Zhao M. Adaptability of varieties to doublecropping in early spring and late summer. Acta Agron Sin, 2011, 37: 1660-1665 (in Chinese with English abstract).

[44] 李立娟, 王美云, 薛庆林, 崔彦宏, 侯海鹏, 葛均筑, 赵明. 黄 淮海双季玉米产量性能与资源效率的研究. 作物学报, 2011, 37: 1229-1234.

Li L J, Wang M Y, Xue Q L, Cui Y H, Hou H P, Ge J Z, Zhao M. Yield performance and resource efficiency of double-cropping maize in the Yellow, Huai and Hai river valleys region. Acta Agron Sin, 2011, 37: 1229-1234 (in Chinese with English abstract).

[45] Meng Q F, Wang H F, Yan P, Pan J X, Lu D J, Cui Z L, Zhang F S, Chen X P. Designing a new cropping system for high productivity and sustainable water usage under climate change. Sci Rep, 2017, 7: 41587.

[46] 周宝元, 王志敏, 岳阳, 马玮, 赵明. 冬小麦-夏玉米与双季玉 米种植模式产量及光温资源利用特征比较. 作物学报, 2015, 41: 1373-1385.

Zhou B Y, Wang Z M, Yue Y, Ma W, Zhao M. Comparison of yield and resource use efficiency between wheat-maize and maize-maize cropping systems. Acta Agron Sin, 2015, 41: 
1373-1385 (in Chinese with English abstract).

[47] 田北京. 基于玉米高生产力的华北平原不同轮作系产量与水 分利用综合评价. 中国农业大学博士论文, 北京, 2018

Tian B J. Comprehensive Evaluation of Yield and Water Use in Different Rotation System Based on High Productivity of Maize in North China Plain. PhD Dissertation of China Agricultural University, Beijing, China, 2018 (in Chinese with English abstract).

[48] 周宝元, 马玮, 孙雪芳, 丁在松, 李从锋, 赵明. 冬小麦-夏玉 米高产模式周年气候资源分配与利用特征研究. 作物学报, 2019, 45: 589-600.

Zhou B Y, Ma W, Sun X F, Ding Z S, Li C F, Zhao M. Characteristics of annual climate resource distribution and utilization in high-yielding winter wheat-summer maize double cropping system. Acta Agron Sin, 2019, 45: 589-600 (in Chinese with English abstract).

[49] 周宝元, 马玮, 孙雪芳, 高卓晗, 丁在松, 李从锋, 赵明. 播/ 收期对冬小麦-夏玉米一年两熟模式周年气候资源分配与利 用特征的影响. 中国农业科学, 2019, 52: 1501-1517.

Zhou B Y, Ma W, Sun X F, Gao Z H, Ding Z S, Li C F, Zhao M. Effects of different sowing and harvest dates of winter wheat-summer maize under double cropping system on the annual climate resource distribution and utilization. Sci Agric Sin, 2019, 52: 1501-1517 (in Chinese with English abstract).

[50] Hou Y H, Hou G F, Qi H, Chen C Y, Li X L, Zhao M, Dong S T. Analysis of photothermic resource use efficiency and potential increases in crops yield in high-yielding regions of eastern Asia. Aust J Crop Sci, 2012, 6: 784-792.

[51] 李璐璐, 王克如, 谢瑞芝, 明博, 赵否, 李姗姗, 侯鹏, 李少昆. 玉米生理成熟后田间脱水期间的籽粒重量与含水率变化. 中 国农业科学, 2017, 50: 2052-2060.

Li L L, Wang K R, Xie R Z, Ming B, Zhao L, Li S S, Hou P, Li S K. Corn kernel weight and moisture content after physiological maturity in field. Sci Agric Sin, 2017, 50: 2052-2060 (in Chinese with English abstract)

[52] Sun H Y, Shen Y J, Yu Q, Flerchinger G N, Zhang Y Q, Liu C M, Zhang X Y. Effect of precipitation change on water balance and WUE of the winter wheat-summer maize rotation in the North China Plain. Agric Water Manag, 2010, 97: 1139-1145.

[53] Fang Q X, Ma L, Green T R, Yu Q, Wang T D, Ahuja L R. Water resources and water use efficiency in the North China Plain: Current status and agronomic management options. Agric Water Manag, 2010, 97: 1102-1116. 